\title{
Transaction Costs Data Impact on Process Self- Organization Evaluation of Quality Management System
}

\author{
Yury Klochkov ${ }^{1,2 *}$ \\ ${ }^{1}$ Peter the Great St.Petersburg Polytechnic University, Polytechnicheskaya, 29, St.Petersburg, 195251, \\ Russia \\ ${ }^{2}$ Far Eastern State Technical Fisheries University, Lugovaya 52B, Vladivostok, 690087 Russian \\ Federation
}

\begin{abstract}
This paper will focus on the transaction costs analysis approach to estimating the level of quality management systems self-organization. It became possible to consider transaction costs in quality management systems with the reclassification of consumer. A suggested classification of consumers includes both "external' and "internal" consumers and also "hidden" and "latent" consumers. Another approach of accounting costs and consumers data allowed us to analyze quality management systems by the share and the level of self-organization.
\end{abstract}

\section{Introduction}

A key principle of quality management system is a "direct targeting", which provides a company with a sustained competitive position in the market. This principle and its methods allow us to get the following concept idea: a quality is a characteristic of a product and processes, which is set by a consumer, the level of which shows the level of competitiveness of an organization [1-3]. This is compatible with the ISO 9000 notation, as the standard says that a quality is the level of compliance of inherent characteristics to requirements. The requirements from their side are both expectations and intentions of the parties concerned. Consequently, by realizing these expectations and intentions, the company provides itself with the competitive position.

\section{Key research findings}

Nowadays according to ISO 9001 there are the following types of consumers:

- external

- internal

External consumers build up specifications, buy products and use them. Internal consumers (employees) develop a design and production process, produce and sell products. But in any economic reality there is a consumer that does not have any possibility to express

* Corresponding author: y.kloch@gmail.com 
his opinion about a product directly to the producer. This happens in case of outsourcing processes when it is not profitable to tell the outsourcer the name of the end-product customer [4]. In this case, according to outsourcer, a hidden consumer appears the satisfaction and loyalty of which is not possible to estimate.

Modern companies often use outsourcers in order to use the latest scientific and technical achievements to produce competitive products of high quality on one hand, and on the other hand to attract qualified specialists in their own business processes. This practice helps to reduce costs on end production.

To design mathematical models of the mentioned process development we used in our research the manuscripts of such Russian and foreign scientists as N.Wiener, N.V. Diligenskiy, S.P. Kapitsa, S.P.Kurdyumov, G.G.Malinetskiy, J.Nikolis, G.P.Poveschenko, D.S.Chernavskiy, etc.

To estimate the performance of the process let us use the ratio of the product quality to the time spent on its production (labor intensity). The quality of product is shown in monetary value, which corresponds to acquisition cost [5-7].

$$
\Pi_{i}=\frac{P(t)}{t_{i}}=\frac{\sum_{j=1}^{n} p_{j}(t) \cdot k_{j}(t)}{t_{i}}
$$

where $\mathrm{P}(\mathrm{t})$ - the product quality level of the process in monetary level;

$\mathrm{p} \_\mathrm{j}(\mathrm{t})$ - the level of intermediate product quality;

$\mathrm{k} \_\mathrm{j}(\mathrm{t})$-the intermediate product coefficient that defines its significance for the end-product (yield);

$\mathrm{t} \_\mathrm{i}$ - the time spent on the production (labor intensity).

Values $p_{j} j(t)$ and $k j j(t)$ are functions of time and they can significantly change. The formula (1) can consider the average lifetime of a resource by dividing numerator and denominator by it, then:

$$
\Pi_{i}=\frac{P(t) \cdot K}{K \cdot t_{i}}=\frac{K \cdot \sum_{j=1}^{n} p_{j}(t) \cdot k_{j}(t)}{T_{i}}
$$

where $\mathrm{K}$ - the average time of a resource usage;

$\mathrm{P}(\mathrm{t})$ - the product quality level of the process in monetary value;

$p_{\ldots} j(t)$-the intermediate product quality level of the process;

$\mathrm{k} \_\mathrm{j}(\mathrm{t})$ - the intermediate product coefficient that defines its significance for the endproduct (yield);

$\mathrm{t}$ i - the time spent on the production;

$\bar{T}_{-}{ }_{i}=\mathrm{K} \cdot \mathrm{t} \_\mathrm{i}-$ the total time spent on production and the resource usage.

Dividing both parts of equation (2) by the value $K \cdot S(t)$ we will get the evaluation of process efficiency of a quality management system.

$$
e_{i}=\frac{\Pi_{i}}{K \cdot S(t)}=\frac{P(t) \cdot K}{K \cdot S(t) \cdot T_{i}}=\frac{P(t)}{S(t) \cdot T_{i}}
$$

where $\mathrm{S}(\mathrm{t})$ - the time spent on resource usage;

$\mathrm{K}$ - the average time of resource usage;

$\mathrm{P}(\mathrm{t})$ - the product quality level of the process in monetary level;

$\mathrm{T}_{-} \mathrm{i}$-the total time spent on production and the resource usage.

The value $\frac{P(t)}{S(t)}$ shows the reasonability of the product output. In case when this relation is less or equal to unity, then the company may not expect to be competitive. Only when the 
relation $\frac{P(t)}{S(t)}$ is more than unity we can expect the development of production and processes of quality management systems.

It is a well-known fact that the processes of quality management systems has been constantly developing, because the basis of any manufacturing organization is a qualified personnel, the aim of which is to upgrade their skills. To design a mathematical model of analyzing the level of process development, we use a known simulation algorithm of selforganizing systems; the model view illustration is the following:

where $\mathrm{dX} / \mathrm{dt}$ - the first derivative;

$$
X(t)=\varphi(o) \frac{d X}{d t}
$$

$\varphi(0)$ - the function characterizing limitation of resources.

Any specific quality management system is known to have several processes, then (4) a differential system becomes n-dimensional. [8]

$$
\frac{X_{i}}{d_{x}}=\varphi\left(o_{i}, \ldots o_{n}\right)
$$

It follows that the process development depends on the volume of quality management system resources. Therefore, the process development model shows the constraint analysis. Having resources of quality management system limited and taking into consideration that these resources have to be distributed among all processes, we conclude that these processes have the role of competitors competing for exact amount of resources. Then, we can add the potential value of process development, which can be shown by averaging all e_i (3).

$$
E(t)=\sum_{i=1}^{n} e_{i} \cdot \varphi_{i}(o)
$$

where $\varphi_{-} \mathrm{i}(\mathrm{t})$ - a relative part of resources for i-process;

e_i - estimation of process effectiveness.

Then we can suppose that the difference of development potentials characterizes the constraint function.

$$
\phi_{\mathrm{i}}(\mathrm{t})=\mathrm{E}_{\mathrm{i}}-\mathrm{E}(\mathrm{t})
$$

So, we get a system of nonlinear differential equations:

Such system has the first integral:

$$
\frac{X_{i}}{d x_{i}}=E_{i}-E(t)=\sum_{j=1}^{n}\left(e_{i}-e_{j}\right) \phi_{j}
$$

$$
\sum_{i=1}^{n} X_{i}(t)=1
$$

which shows the condition of competitiveness.

A total analytical solution for the mentioned system can be received in a following way.

Out of (8) it follows, that the difference of process development levels equals to the difference of effectiveness of their development. We admit that the process completely realizes its potential. 


$$
\frac{X_{i}}{d_{x}}-\frac{X_{m}}{d x_{m}}=e_{i}-e_{m}
$$

If we add conventional signs:

$$
\mathrm{y}_{\mathrm{im}}=\frac{\mathrm{X}_{\mathrm{i}}}{\mathrm{X}_{\mathrm{m}}}
$$

Then we get the following differential equation:

$$
y_{\text {im }}=y_{i m}\left(e_{i}-e_{m}\right)
$$

As a result, there is dependence:

$$
\mathrm{X}_{\mathrm{i}}(\mathrm{t})=\frac{\mathrm{X}_{\mathrm{i}}\left(\mathrm{t}_{0}\right)}{\sum_{\mathrm{m}=1}^{\mathrm{n}} \mathrm{X}_{\mathrm{m}}\left(\mathrm{t}_{0}\right) \exp \left[\left(\mathrm{e}_{\mathrm{m}}-\mathrm{e}_{\mathrm{i}}\right)-\left(\mathrm{t}-\mathrm{t}_{0}\right)\right]}
$$

where t_ 0 - fixed, the initial instant;

$\mathrm{X} \_\mathrm{i}\left(\mathrm{t} \_\overline{0}\right)$ - initial data at the moment of building a quality management system.

Formula (13) corresponds to the logistic model structure and defines the results of selforganizing processes simulation. It shows that in time the difference of the levels of quality management processes plays a bigger role for the effectiveness of quality management system, which means the more is the difference in quality standards, the less effective is the quality management system, and consequently, the enterprise is not competitive.

Using known methods of communication with a consumer, a manufacturer tries to define the level of satisfaction and loyalty most precisely. If consumer satisfaction is the value of output product quality, then its level defines the possibility of buying the product at the exact period of time. The loyalty is a characteristic that defines the possibility of long-term orders. Consequently, product quality index shows the level of satisfaction. The business processes quality index defines the level of loyalty, so it guarantees long-term relationships. As the loyalty is defined by the development level of the quality management systems processes and a hidden consumer does not have a possibility to estimate the quality, then he does not have any level of loyalty (Table 1).

The hidden consumer is a consumer, whose opinion of a product is not possible to know on the stage of marketing and designing $[9,10]$.

The hidden consumer appears in the following two situations:

In case of outsourcing companies;

In case when some part of production process takes place on the consumer territory (installation of utility systems: air conditioning and ventilation; fire security and others).

Besides, there are requirements for a representative selection while developing the estimation procedure of consumer satisfaction and loyalty, which means there are always some customers, whose opinion is not estimated.

So, taking into consideration the methods of communication with consumer, we can see that consumer is getting a latency, which can also be measured in percentage as well as satisfaction and loyalty.

A latent consumer is a consumer, which is out of satisfaction estimation procedure.

A latent characteristic of a product is a characteristic, which was not used in estimating the satisfaction of a consumer. Consequently, a characteristic of latency is used for:

- customers, that did not participate in the toll;

- characteristics of a product or a process, that are not included into consumers opinion estimation.

The reasons of having latent consumers:

- the lack of enough time for analysis; 
- limited resources.

Table 1. Types of consumers.

\begin{tabular}{|c|c|c|c|c|c|c|}
\hline & umers & Characteristic & & Properties & & \multirow{9}{*}{ 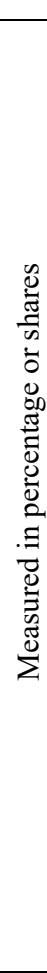 } \\
\hline \multirow{8}{*}{ 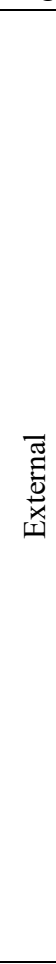 } & \multirow{6}{*}{ Real } & $\begin{array}{c}\text { Defines } \\
\text { specifications } \\
\text { and order } \\
\text { volume }\end{array}$ & \multirow{4}{*}{$\begin{array}{l}\text { Relative to the } \\
\text { product and } \\
\text { processes }\end{array}$} & \multirow[t]{2}{*}{$\begin{array}{l}\text { Satisfied// } \\
\text { Unsatisfied }\end{array}$} & \multirow{2}{*}{$\begin{array}{l}\text { Is } \\
\text { guaranteed } \\
\text { by the } \\
\text { quality of } \\
\text { product }\end{array}$} & \\
\hline & & \multirow{2}{*}{ Pays } & & & & \\
\hline & & & & \multirow{2}{*}{ Loyal/ Disloyal } & \multirow{2}{*}{$\begin{array}{c}\text { Is } \\
\text { guaranteed } \\
\text { by the } \\
\text { quality of } \\
\text { process }\end{array}$} & \\
\hline & & \multirow{2}{*}{ Uses } & & & & \\
\hline & & & \multirow{2}{*}{$\begin{array}{c}\text { Relative to } \\
\text { communication } \\
\text { methods }\end{array}$} & \multirow{2}{*}{$\begin{array}{l}\text { Estimated/ } \\
\text { Latent }\end{array}$} & $\begin{array}{l}\text { By the } \\
\text { product } \\
\text { properties }\end{array}$ & \\
\hline & & Estimates & & & $\begin{array}{l}\text { Relative to } \\
\text { the } \\
\text { estimation } \\
\text { groups }\end{array}$ & \\
\hline & \multirow[t]{2}{*}{ Hidden } & Uses & $\begin{array}{l}\text { Relative to the } \\
\text { product }\end{array}$ & $\begin{array}{l}\text { Satisfied/ } \\
\text { Unsatisfied }\end{array}$ & $\begin{array}{c}\text { Is } \\
\text { guaranteed } \\
\text { by the } \\
\text { quality of } \\
\text { product } \\
\end{array}$ & \\
\hline & & Estimates & $\begin{array}{c}\text { Relative to } \\
\text { communication } \\
\text { methods }\end{array}$ & $\begin{array}{c}\text { Latent } \\
\text { (latency level } \\
100 \% \text { ) }\end{array}$ & $\begin{array}{l}\text { Relative to } \\
\text { the } \\
\text { estimation }\end{array}$ & \\
\hline \multirow{4}{*}{\multicolumn{2}{|c|}{ 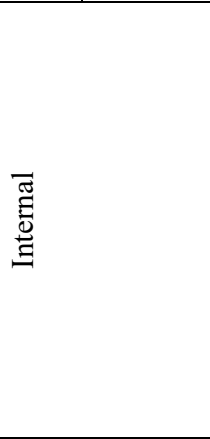 }} & Engineers & \multirow{2}{*}{$\begin{array}{l}\text { Relative to the } \\
\text { product and } \\
\text { processes }\end{array}$} & $\begin{array}{c}\text { Satisfied/ } \\
\text { Unsatisfied }\end{array}$ & \multirow{2}{*}{$\begin{array}{c}\text { Is } \\
\text { guaranteed } \\
\text { by the staff } \\
\text { management } \\
\text { system }\end{array}$} & \\
\hline & & \multirow{2}{*}{ Produces } & & Loyal/ Disloyal & & \\
\hline & & & \multirow{2}{*}{$\begin{array}{l}\text { Relative to } \\
\text { communication } \\
\text { methods }\end{array}$} & \multirow[b]{2}{*}{$\begin{array}{l}\text { Estimated/ } \\
\text { Latent }\end{array}$} & $\begin{array}{c}\text { Relative to } \\
\text { evaluation } \\
\text { criteria }\end{array}$ & \\
\hline & & Sells & & & $\begin{array}{l}\text { Relative to } \\
\text { the } \\
\text { estimation } \\
\text { groups }\end{array}$ & \\
\hline
\end{tabular}

Nigel Hill, Bill Self, Greg Roche, etc. in their research of satisfaction and loyalty level of a consumer highlight the issue of a representative selection of a consumer. In their papers, too much attention has been paid to the minimum number of respondents. But it is important to consider that consumers have a different value for enterprises, because each of them guarantees a specific level of competitiveness or income.

Therefore, to define a list of consumers, the opinion of whom is necessary to estimate for the management analysis (ISO 9001), it is important to use a "competitiveness level" criteria.

Besides, if the estimation of consumer satisfaction does not consider the level of enterprise competitiveness, then the conclusions and decisions (correcting and preventing measures) may not correspond to the requirements of those consumers, who define the competitive position of an enterprise in the market $[11,12]$. 
The estimation of the competitiveness level of an enterprise must take into account the following factors:

- product market has to be classified by categories: type of product, geographic location, price;

- the possibility of long-term relations, for example, by analyzing the terms of cooperation;

- groups of consumers (by type of products, by geographic location, by price, by terms of cooperation, etc);

- other factors set by the management concerning strategic plans of enterprise development.

If we consider the level of consumer satisfaction (real and hidden consumer) defines the volume of sold products, then the level of satisfaction of hidden consumer can be calculated by formula 14 .

$$
\mathrm{L}_{\text {hid }}=\frac{2\left(\frac{\mathrm{V}_{\mathrm{s}}}{\mathrm{V}_{\mathrm{p}}}\right)-\mathrm{K}_{\mathrm{r}} \mathrm{L}_{\mathbf{r}}}{\mathrm{K}_{\mathrm{hid}}}
$$

where L_hid - the level of satisfaction of hidden consumer;

$\mathrm{Lr}$ - the level of satisfaction of real consumer;

$\mathrm{Vs}$ - the level of products sold;

$\mathrm{Vp}$ - planned volume of products sales;

$\mathrm{Kr}$ - influence coefficient of a real consumer on the choice of outsourcer;

Khid -influence coefficient of a hidden consumer on the choice of outsourcer;

BesidesK_hid+K_r=1.

The appearance of hidden and latent consumer leads to the increase of the share of selforganizing in processes of quality management systems, because the evaluation of such consumers requirements and as a result the forecasting the level of product competitiveness and the planning of production mostly depends on staff experience [13]. So, the increase of self-organizing is an objective reason of quality management development which is cause by the modern tendencies of the market.

As self-controlled processes influence on an enterprise both in positive and negative way, there is a need in adequate ways of estimation, analysis, reaction and support of such processes that guarantee a competitive development of the organization.

To estimate and analyze a share of self-organization we take the correlation of in-process organizational and transaction costs. If transaction costs are higher than the organizational costs, then consequently the role of self-organization is high [14].

Transaction and organizational costs are interrelated values, the increase of ones leads to the decrease of another and vice versa.

Transaction costs of quality management system business processes are the following:

- search of customer data, supplier and outsourcer data;

- quality standard analysis of output product;

- decision making and its consequences;

- development of new manufacturing processes;

- process optimization;

- advanced professional training;

- evaluation of consumer satisfaction level;

- and others.

Organizational costs of quality management system business processes are the following:

- standards engineering and support;

- production certification;

- personnel certification; 
- product identification and traceability;

- product control;

- safety systems application;

- and others.

If we estimate self-organization as a vector variable, then vector variable is a share of self-organization, which depends on objective factors, such as the development of construction and technology, a hidden consumer and others. Vector direction describes the level of self-organization, which depends on subjective factors, such as the development of quality management system of an enterprise, the level of standardization and others (Fig. 1).

Therefore, a share of self-organization is a variable based independently on the management of enterprise, and the level of self-organization is guaranteed by an adequate quality management system.

$$
\mathrm{K}_{1}=\frac{\mathrm{Cc}}{\mathrm{Cn}+\mathrm{Cc}}
$$

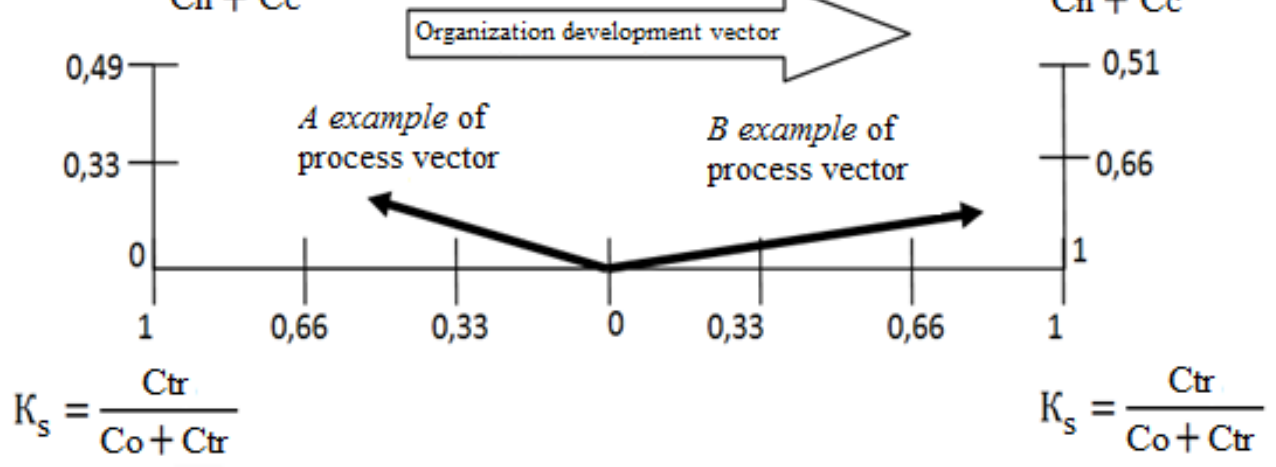

Fig. 1. Self-organization vector

A example of process vector: a share of self-organization is average, the level is low, and process is regressing.

$B$ example of process vector: a share of self-organization is high, the level is high, and process is progressing.

The self-organization share (vector variable) is suggested to estimate based on the theory of transaction and organizational costs [15].

The self-organization level (vector direction) is suggested to estimate based on the theory of transaction costs and quality economics.

The self-organization share in processes of quality management system is suggested to estimate based on the following criteria (15).

where Co - organizational costs;

$$
\mathrm{K}_{\mathrm{s}}=\frac{\mathrm{C}_{\mathrm{tr}}}{\mathrm{C}_{\mathrm{o}}+\mathrm{C}_{\mathrm{tr}}}
$$

\section{$\mathrm{Ctr}$ - transaction costs.}

If the value of $K_{s}$ index is near to zero, the lower is the share of self-management. We calculate the self-management level of processes of quality management using the following criteria (16).

$$
\mathrm{K}_{l}=\frac{\mathrm{C}_{\mathrm{c}}}{\mathrm{C}_{\mathrm{n}}+\mathrm{C}_{\mathrm{c}}}
$$

where $\mathrm{Cn}$ - business process costs of non-conformance;

$\mathrm{Cc}-$ business process costs of conformance. 
If the value of $\mathrm{Kl}$ index is near to zero, the lower is effectiveness of self-management. Consequently, in case when self-organization share in quality management processes is high according to calculations results, it is necessary to change evaluation criteria of process effectiveness (ISO 9001) and include calculation results of $\mathrm{Kl}$ in "management analysis" (ISO 9001).

The increase of self-organization share leads to the fact that some functions of manager are delegated to the executives. (Fig. 2), which is possible to describe in process map, as a documented procedure that gives a staff required authority and shows responsibilities along the (Table 2).

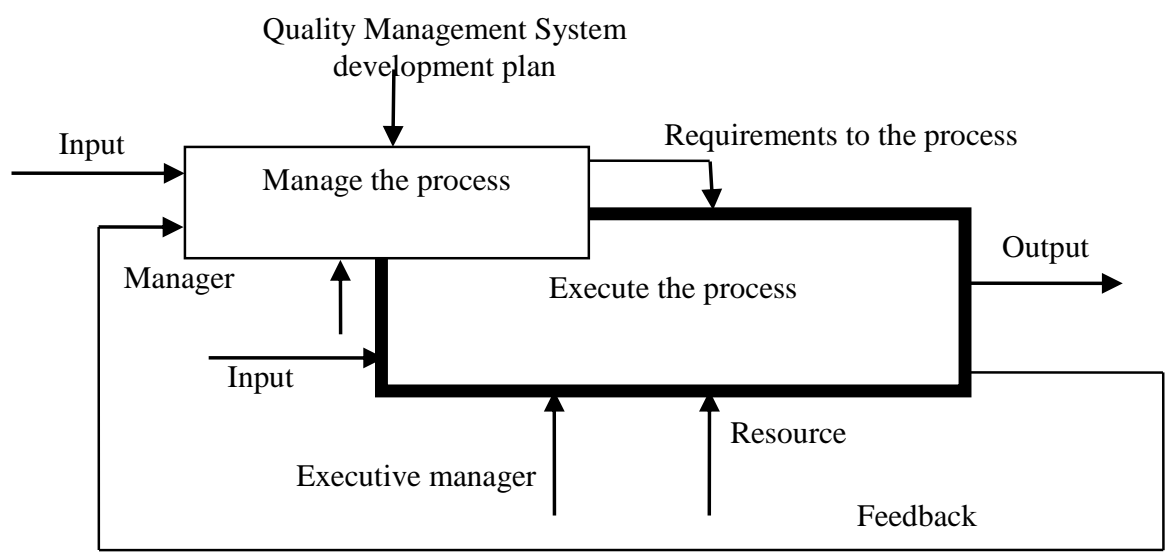

Fig. 2. Production and management processes integration

Table 2. Sample of high self-organization process map

\begin{tabular}{|c|c|c|c|c|c|c|}
\hline \multicolumn{2}{|c|}{ Process name } & \multicolumn{2}{c|}{$\begin{array}{c}\text { Change } \\
\text { number }\end{array}$} & \multicolumn{2}{|c|}{ Data. } & Page / \\
\hline \multirow{2}{*}{ № } & \multirow{2}{*}{$\begin{array}{c}\text { Process } \\
\text { chart }\end{array}$} & $\begin{array}{c}\text { Works (procedures, } \\
\text { functions) in process }\end{array}$ & $\begin{array}{c}\text { Responsible } \\
\text { personnel }\end{array}$ & $\begin{array}{c}\text { Documents/ } \\
\text { entry } \\
\text { format }\end{array}$ & Appendix \\
\cline { 3 - 6 } & 2 & Executive & Manager & & 6 & 7 \\
\hline 1 & 3 & 4 & 5 & 6 & \\
\hline
\end{tabular}

With such development the significance of self-esteem procedures is getting more important, audit is aimed to integrate a separate process in the quality management system. Besides, according to the experience of fulfilling the requirements of ISO 9001 (management analysis), it is partially carried out by the manager of the process, for example he analyses the level of consumer and creates a plan of improving the product.

\section{Conclusion}

Monitoring of a process of a quality management system (ISO 9001) will be changed concerning the estimation of the process management. So, if the controllability of a process with a low self-organization was estimated by the analysis of correcting and preventing events, the dynamics of effectiveness index change and audit processes, but with a high self- 
organization it becomes possible to estimate controllability not only by the process results, but during the process by evaluating the realization of delegated functions of a manager.

To realize a "system principle" in enterprise with a high self-organization of processes it is necessary to estimate the integration of a single process into current quality management system. This is recommended to carry out by analyzing process control index (the level of acceptance by auditors, the level of effectiveness of preventing events, the evaluation of effectiveness index dynamics of a process based on control charts), integrity (on the stage of planning and correction especially) and governance.

With an increase of self-organization the possibility of shifting the process development vector from the vector of enterprise development itself increases. Among them is IT, which will allow applying standardized quality management methods when needed.

The article is published within the "Development of a Competitiveness Enhancement Methods of Fishing Fleet" (No.121031300159-6) government program of the Federal Agency for Fishery.

\section{References}

1. V.S. Ptitsyna, M.S. Kulikova, V.A. Vasiliev and S.A. Chernogorskiy, The Introduction of Information Technology in Business Processes as a Method of Quality Improvement, vol. 666, 2019, doi:10.1088/1757-899X/666/1/012059.

2. A. Mittal, and P. Gupta. "An Empirical Study on Enhancing Product Quality and Customer Satisfaction using Quality Assurance Approach in an Indian Manufacturing Industry." Internaional Journal of Mathematical, Engineering and Management Sciences, vol. 6, no. 3, 2021, pp. 878-893, doi:10.33889/ijmems.2021.6.3.052.

3. R. Wolniak, "The Concept of Operation and Production Control." Production Engineering Archives, vol. 27, no. 2, 2021, pp. 100-107, doi:10.30657/pea.2021.27.12

4. S. Sabirova, V. A. Vasiliev, and S. A. Chernogorskiy. Choosing a Quality Management Method, vol. 666, 2019, doi:10.1088/1757-899X/666/1/012043.

5. L. Sang, et al. "Big Data, Technology Capability and Construction Project Quality: A Cross-Level Investigation." Engineering, Construction and Architectural Management, vol. 28, no. 3, 2021, pp. 706-727, doi:10.1108/ECAM-02-2020-0135.

6. Y. V. Velmakina, V. A. Vasiliev, and S. A. Chernogorskiy. Methodology for Assessing the Performance of the Integrated Management System, vol. 666, 2019, doi:10.1088/1757-899X/666/1/012042.

7. G.A. Stroykov, N.V. Babyr, I.V. Ilin, R.S. Marchenko, "System of Comprehensive Assessment of Project Risks in Energy Industry." International Journal of Engineering, Transactions A: Basics, vol. 34, no. 7, 2021, pp. 1778-1784, doi:10.5829/IJE.2021.34.07A.22.

8. R. Trishch, et al. "Methodology for Multi-Criteria Assessment of Working Conditions as an Object of Qualimetry." Engineering Management in Production and Services, vol. 13, no. 2, 2021, pp. 107-114, doi:10.2478/emj-2021-0016.

9. M. Almasi, S. Khoshfetrat, and M. R. Galankashi. "Sustainable Supplier Selection and Order Allocation Under Risk and Inflation Condition." IEEE Transactions on Engineering Management, vol. 68, no. 3, 2021, pp. 823-837, doi:10.1109/TEM.2019.2903176.

10. T. Adreeva, et al. "Development of Lean Manufacturing in Quality Management System." Quality - Access to Success, vol. 22, no. 181, 2021, pp. 71-75. 
11. P. Dionysopoulou, G. Svarnias, and T. Papailias. "Total Quality Management in Public Sector, Case Study: Customs Service." Regional Science Inquiry, vol. 13, no. 1, 2021, pp. 153-168.

12. I. Gremyr, et al. "Increasing the Value of Quality Management Systems." International Journal of Quality and Service Sciences, 2021, doi:10.1108/IJQSS-10-2020-0170.

13. P. Ondra, "Managing Quality in Industrial Companies: The Empirical Study of Quality Management Systems in the Czech Republic." Serbian Journal of Management, vol. 16, no. 1, 2021, pp. 251-266, doi:10.5937/sjm16-24507.

14. R. Trishch, et al. "Methodology for Multi-Criteria Assessment of Working Conditions as an Object of Qualimetry." Engineering Management in Production and Services, vol. 13, no. 2, 2021, pp. 107-114, doi:10.2478/emj-2021-0016.

15. A. O. Verenikin, F. S. Amirkhanova, and A. Y. Verenikina. Quality Management System Certification in the Russian Software Development Industry, 2021, doi:10.1109/ICITM52822.2021.00011. 